\title{
Silent earthquakes occurring in a stable-unstable transition zone and implications for earthquake prediction
}

\author{
Ichiro Kawasaki \\ Disaster Prevention Research Institute, Kyoto University, Uji, Kyoto 611-0011, Japan
}

(Received December 22, 2003; Revised July 13, 2004; Accepted July 13, 2004)

\begin{abstract}
In the past decade, nine silent earthquakes were documented along the Nankai and the Sagami Troughs in Japan, which form the northwestern margin of the Philippine Sea plate. They occurred in the stable-unstable transition zone at depths of around $30 \mathrm{~km}$ on the subduction interface and were segregated from major asperities of the 1923 Kanto, the 1944 Tonankai and the 1946 Nankai earthquakes. Their equivalent magnitudes were less than 7 and overall slips were less than $0.2 \mathrm{~m}$, one-order smaller than those of the major asperities of ordinary great earthquakes. Moment release rates of the silent earthquakes were less than $10^{14} \mathrm{Nm} / \mathrm{s}$, five-orders smaller than $10^{19} \mathrm{Nm} / \mathrm{s}$ of the great earthquakes. Two methodologies are attempted to obtain order of magnitude estimates of the roughness and friction parameter of source areas of some of the silent earthquakes. One method compares observed waveforms to synthetics with an empirical source time function based on laboratory experiment. The other relates sizes of silent earthquakes to the friction parameter $a-b$.
\end{abstract}

Key words: Silent earthquake, fault roughness, stable-unstable transition zone, Nankai Trough, Sagami Trough.

\section{Introduction}

Great $M w 8$ earthquakes recur at intervals of about 100 years along the Nankai and the Sagami Troughs on the northwestern margin of the Philippine Sea plate, which is subducting at a rate of around 5-6 cm/yr (e.g., Seno et al., 1993). Figure 1 shows a vertical cross section of the distribution of microearthquakes (Nakamura et al., 1997) under southwest Japan. The region labeled (A) is the seismogenic zone where the interplate coupling is strong and major earthquakes recur. (C) is a region where stable sliding is dominant. (B) is the stable-unstable transition zone between $(\mathrm{A})$ and $(\mathrm{C})$, as suggested by geodetic inversion of GPS data by Ito et al. (1999) and Sagiya (1999).

This article consists of two parts: a summary of silent earthquakes recently documented along the Nankai and the Sagami Troughs and two independent order of magnitude estimates of the roughness and friction parameter of the source areas of silent earthquakes on the subduction interface.

\section{Spatial Distribution of Silent Earthquakes}

There have previously been numerous studies on aseismic events: e.g., Pelayo and Wiens (1992) and Kanamori and Kikuchi (1993) from anomalous excitation of long period seismic waves, Beroza and Jordan (1990) from free oscillations and Linde et al. (1988) and Kawasaki et al. (1995) from continuous recordings of crustal strains and tilts. Recently, there were new findings of silent earthquakes with GPS data in the Cascadia (e.g., Dragert et al., 2001), Alaskan (e.g., Freymueller et al., 2002) and Mexican (e.g., Lowry et al., 2001) subduction zones.

Copy right(c) The Society of Geomagnetism and Earth, Planetary and Space Sciences (SGEPSS); The Seismological Society of Japan; The Volcanological Society of Japan; The Geodetic Society of Japan; The Japanese Society for Planetary Sciences; TERRAPUB.
In Japan, there have been 9 silent earthquakes identified in the past decade along the Nankai and the Sagami Troughs, as listed in Table 1 and plotted together with ordinary great earthquakes in Fig. 2. Slow-slip-event is hereafter used as a general term for all aseismic events. $M w a$ is an equivalent magnitude of slow-slip events, first defined by Kawasaki et al. (2001) through a relationship, $\log \mathrm{Moa}=1.5 \mathrm{Mwa}+$ 9.1, where Moa $(\mathrm{Nm})$ is the static moment inverted from geodetic data.

Fujii (1993) obtained a fault plane solution and an interplate moment of the 1970 Chiba silent earthquake (SL1 in Table 1) by an inversion of leveling data from GSI (Geographical Survey Institute, Japan). The source duration time of the event is unknown. Hirose et al. (2000) found the 1989 Tokyo Bay silent earthquake (SL2) ( $M w a$ 5.9) with a source duration time of around 1 day, using continuous recordings of crustal tilts by NIED (National Research Institute of Earth Sciences and Disaster Prevention, Japan). Other events were detected by GPS data of GEONET, which was established in 1994 by GSI (e.g., Hatanaka et al., 2003). Sagiya (2004) obtained fault models of the offshore Boso Peninsula silent earthquakes that recurred in 1996 ( $M w a$ 6, source duration time of a few days, SL3) and in 2002 ( $M w a$ 6.5, source duration time of a few days, SL8). Hirose et al. (1999) identified the 1997 Bungo Channel silent earthquake (SL4) of Mwa 6.6 that had a source duration time of around 1 year and recurred in 2003 (SL9), as reported by GSI (2004). Recently, the Tokai silent earthquake (SL7) initiated in 2001 (Kimata et al., 2002) and is still active with a current size of Mwa 7.0 (GSI, 2003b). All of the silent earthquakes were located between the subducting Philippine Sea and the overriding Eurasian plates, except the two Offshore-Choshi silent earthquakes that recurred in 1999 (Mwa 5.6, source duration time of a few days, SL5) (Harada et al., 2000) and in 2000 


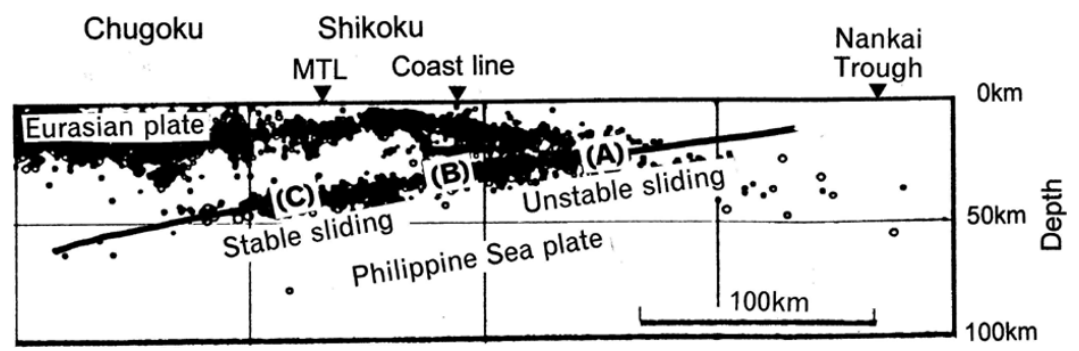

Fig. 1. Seismic cross section subparallel to the latitudinal line at longitude 133E across the Nankai Trough and Chugoku and Shikoku districts, where the Philippine Sea plate is subducting beneath the overriding Eurasian plate. MTL is median tectonic line. The area labeled (A) is the seismogenic region. (C) is a region where stable sliding on the subduction interface is dominant. (B) is the stable-unstable transition zone between (A) and (C). Modified from the panel $\mathrm{E}$ in figure 8 of Nakamura et al. (1997).

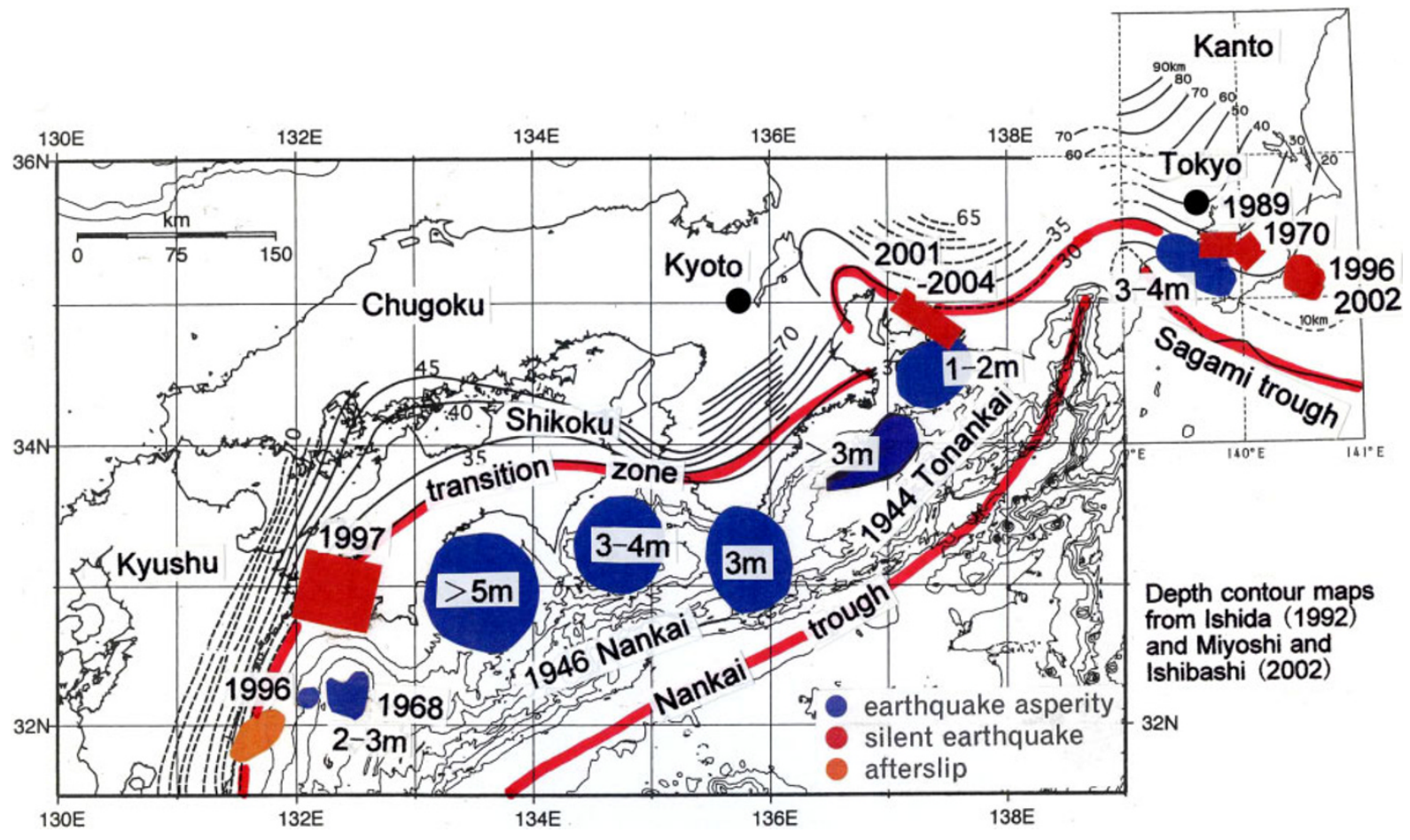

Fig. 2. Distribution of the silent earthquakes (solid), the afterslips (solid with course hatching) and major asperities (fine hatching) of $M w 8$ class interplate earthquakes. Plate-depth contours are after Miyoshi and Ishibashi (2002) for southwest Japan including the Nankai Trough and Ishida (1992) for the Kanto district, including the Sagami Trough.

(Mwa 5.6, source duration time of a few days, SL6) (Hirose et al., 2001) on the subduction interface of the Pacific plate. It should be noted that the source duration time, $T o$, widely ranged from around 1 minute for the great $M w 8$ earthquakes to a few years for the Tokai silent earthquake. Focal mechanisms of the slow-slip-events can be commonly interpreted to be low angle thrusting on the plate boundary. Seismic activity was generally not associated with these events, except for low level seismicity related to the two Boso Peninsula silent earthquakes (Sagiya, 2004). Obara (2002) discovered nonvolcanic deep tremors at depths of the stable-unstable transition zone, but their relation to the slow-slip-events is unknown.

Figure 2 shows the spatial distribution of the slow-slipevents and major asperities of the $M w 8$ interplate earthquakes. Asperities of the 1923 Kanto and the 1944 Tonankai earthquakes were obtained by seismic waveform inversion by Wald and Somerville (1995) and Kikuchi et al. (2003), respectively. Asperities of the 1946 Nankai earthquake are defined here as the areas which show large slips in all the inversion results obtained from leveling (Sagiya and Thatcher, 1999), tsunami (Tanioka and Satake, 2001) and seismic intensity data (Kanda et al., 2003). Figure 2 displays that the slow-slip-events are separated from the major asperities. This kind of segregation was first reported by Yagi et al. (2001) for the asperity and the afterslip area of the 1996 Hyuganada earthquake. Average amount of slips of major asperities of the $M w 8$ class earthquakes were around 3-5 $\mathrm{m}$, except for the northeast smaller asperity of the Tonankai earthquake with a slip of 1-2 m. Average amounts of slips for the silent earthquakes were less than $0.2 \mathrm{~m}$, one-order smaller than those of the major asperities. In other words, the silent earthquakes occurred in the transition zone between the seismogenic zone and the zone where stable sliding is dominant. The depth of the transition zone was suggested to be around $30 \mathrm{~km}$ along the Nankai Trough by thermal mod- 
Table 1. Silent earthquakes, afterslips and $M w 8$ class ordinary earthquakes along the Sagami and the Nankai Troughs. EQ1 to EQ3 are $M w 8$ class giant earthquakes that occurred along the Sagami and the Nankai Troughs. SL1 to SL8 are silent earthquakes recently documented in Japan. AS1 and AS2 are afterslips. Mo and Moa are moments for ordinary and silent earthquakes, respectively. $M w$ is moment magnitude. $M w a$ is equivalent magnitude estimated from Moa through the relationship, $\log M o a=1.5 \times M w a+9.1$. Do is an overall slip. To is a source duration time. S, Leveling, Tilt and GPS in Data type column denote seismic records, levelling, continuous recording of crustal tilt, and GPS, respectively. References are (1) Wald and Somerville (1995), (2) Kikuchi et al. (2003), (3) Kanamori (1972), (4) Fujii (1993), (5) Hirose et al. (2000), (6) Sagiya (2004), (7) Hirose et al. (1999), (8) Harada et al. (2000), (9) Hirose et al. (2001), (10) GSI (2003b), (11) GSI (2003a), (12) GSI (2004) and (13) Yagi et al. (2001).

\begin{tabular}{|c|c|c|c|c|c|c|c|c|c|}
\hline No. & Event & $M w$ & $M w a$ & $\begin{array}{c}M o \\
10^{18} \mathrm{Nm}\end{array}$ & Moa & $\begin{array}{c}D o \\
\mathrm{~m}\end{array}$ & $\begin{array}{l}\text { To } \\
\text { day }\end{array}$ & Ref. & $\begin{array}{l}\text { Data } \\
\text { type }\end{array}$ \\
\hline EQ1 & 1923 Kanto & 7.9 & & $700-800$ & & 3.5 & 0.0008 & (1) & $\mathrm{S}$ \\
\hline EQ2 & 1944 Tonankai & 7.9 & & 960 & & 2.9 & 0.0007 & (2) & $\mathrm{S}$ \\
\hline EQ3 & 1946 Nankai & 8.0 & & 1500 & & 3.1 & 0.001 & (3) & S \\
\hline SL1 & 1970 Chiba & & 6.5 & & 7.6 & 0.4 & & (4) & Leveling \\
\hline SL2 & 1989 Tokyo Bay & & 5.9 & & 0.75 & 0.02 & $\sim 1$ & (5) & Tilt \\
\hline SL3 & 1996 Boso & & 6.0 & & 1 & 0.1 & $\sim 5$ & (6) & GPS \\
\hline SL4 & 1997 Bungo Channel & & 6.6 & & 11 & 0.18 & $\sim 300$ & (7) & GPS \\
\hline SL5 & 1999 Choshi-oki & & 5.6 & & 0.33 & 0.03 & $\sim 5$ & (8) & GPS \\
\hline SL6 & 2000 Choshi-oki & & 6.1 & & 1.7 & 0.17 & $2 \sim 3$ & (9) & GPS \\
\hline SL7 & 2001-ongoing Tokai & & 7.0 & & 40 & 0.20 & $\sim 1500$ & (10) & GPS \\
\hline SL8 & 2002 Boso & & 6.5 & & $\sim 10$ & 0.1 & $\sim 10$ & (11) & GPS \\
\hline SL9 & 2003 Bungo-Channel & & 6.6 & & 11 & 0.11 & $\sim 60$ & (12) & GPS \\
\hline AS1 & 1996 Hyuga-nada (a) & & 6.8 & & 17 & 0.1 & $\sim 50$ & (13) & GPS \\
\hline AS2 & 1996 Hyuga-nada (b) & & 6.8 & & 20 & 0.1 & $\sim 50$ & (13) & $\mathrm{jk}, \mathrm{GPS}$ \\
\hline
\end{tabular}

els (e.g., Hyndman and Wang, 1993) and geodetic inversions (e.g., Ito et al., 1999).

\section{A Source Parameter Gap between Ordinary and Silent Earthquakes}

Figure 3 is a moment and moment-rate diagram. The fault length $L$ is calculated using the relationship $M o=$ $2 \times 10^{6} \times L^{3}$ following Sato (1979), when plotting the iso$V r$ lines in Fig. 3. It should be noted that there is a gap of 5 orders of moment rates between $10^{14} \mathrm{Nm} / \mathrm{s}$ of the silent earthquakes and $10^{19} \mathrm{Nm} / \mathrm{s}$ of the ordinary earthquakes as displayed in Fig. 3.

The zone between the two iso- $V r$ lines of $1 \mathrm{~mm} / \mathrm{s}$ and $1 \mathrm{~m} / \mathrm{s}$ (source duration times from days to years) is called the "GPS band" in this paper because all of the silent earthquakes in this zone were detected by GPS data. The other zone between $1 \mathrm{~m} / \mathrm{s}$ and $1 \mathrm{~km} / \mathrm{s}$ is hereafter called the "strainmeter and tiltmeter band" because the Tokyo Bay silent event (Hirose et al., 2000) in this zone was detected by tiltmeter records.

There seem to be confusions on naming conventions of slow-slip-events. The present author would like to propose a new convention which names slow-slip-events in the strainmeter/tiltmeter band with source duration time of hours, "slow earthquakes" and events in the GPS band with source duration times of days to years, "silent earthquakes". Also afterslips are not included as slow/silent earthquakes.

Table 2 shows the correspondence between the previous classification of slow-slip-events by Beroza and Jordan (1990), phases of the theoretical model of earthquake nucleation of Shibazaki and Matsu'ura (1998), some of the silent earthquakes and the new naming convention proposed. The fastest event among the silent earthquakes was the 1989 Tokyo Bay silent earthquake. Thus, there is a gap of 3 orders in rupture velocity between the silent earthquakes in the
Table 1 and the ordinary earthquakes and there were no slowslip-events that accelerated to the "dynamic but slow rupture growth" of Shibazaki and Matsu'ura (1998).

\section{Summary of Silent Earthquakes and Issues Re- lated to Earthquake Prediction}

We summarize below the basic features of the slow-slipevents along the Nankai and the Sagami Troughs detected to date.

(S1) There was a segregation between major asperities of $M w 8$ class earthquakes and source areas of the slow-slipevents.

(S2) Major asperities of the $M w 8$ class earthquakes were shallower than about $30 \mathrm{~km}$ in the seismogenic zone. Overall slips were about 3-5 m.

(S3) The silent earthquakes occurred in the stable-unstable transition zone at depths of around $30 \mathrm{~km}$.

(S4) The silent earthquakes had $M w a$ less than 7 and overall slips were less than $0.2 \mathrm{~m}$, one-order smaller than the major asperities of the ordinary $M w 8$ earthquakes.

(S5) The silent earthquakes were associated with little seismic activity.

(S6) Moment release rates of the silent earthquakes along the Sagami Trough were one- or two-orders larger than those along the Nankai Trough.

(S7) There was a gap of 5-orders in the moment release rates between the silent earthquakes and the ordinary earthquakes. There were no slow earthquakes that reached the "dynamic but slow rupture growth".

It is appropriate to mention 'slow' but seismic initial phases, as reported by Ellsworth and Beroza (1998). These observations could be described as slow-slip-events in their early stage, then seismically observable in their later stages as the seismic initial phase, if the forthcoming earthquake is large enough. 
Table 2. Classification of slow-slip-events. Correspondence between classification of slow-slip-events by Beroza and Jordan (1990), phases of theoretical model of earthquake nucleation of Shibazaki and Matsu'ura (1998), some of silent earthquakes in Fig. 1 and naming convention proposed in this paper. $\mathrm{Vr}$ is rupture propagation velocity.

\begin{tabular}{|c|c|c|c|c|}
\hline $\mathrm{Vr}$ & $\begin{array}{c}\text { Beroza and } \\
\text { Jordan (1990) }\end{array}$ & $\begin{array}{c}\text { Shibazaki and } \\
\text { Matsu'ura (1998) }\end{array}$ & $\begin{array}{c}\text { Silent } \\
\text { earthquakes }\end{array}$ & $\begin{array}{l}\text { Naming } \\
\text { proposed }\end{array}$ \\
\hline $1 \mathrm{~km} / \mathrm{s}$ & & dynamic rupture & & - \\
\hline $0.1 \mathrm{~km} / \mathrm{s}$ & slow eq. & dynamic but slow & & slow eq. \\
\hline $10 \mathrm{~m} / \mathrm{s}$ & silent eq. & rupture growth & & \\
\hline $1 \mathrm{~m} / \mathrm{s}$ & & & 1989 Tokyo Bay & - \\
\hline $10 \mathrm{~cm} / \mathrm{s}$ & creep event & & & \\
\hline $1 \mathrm{~cm} / \mathrm{s}$ & & quasi-static & 1997 Bungo & silent eq. \\
\hline $1 \mathrm{~mm} / \mathrm{s}$ & & nucleation & 2001 Tokai & \\
\hline
\end{tabular}

\section{Moment--Moment Rate diagram}

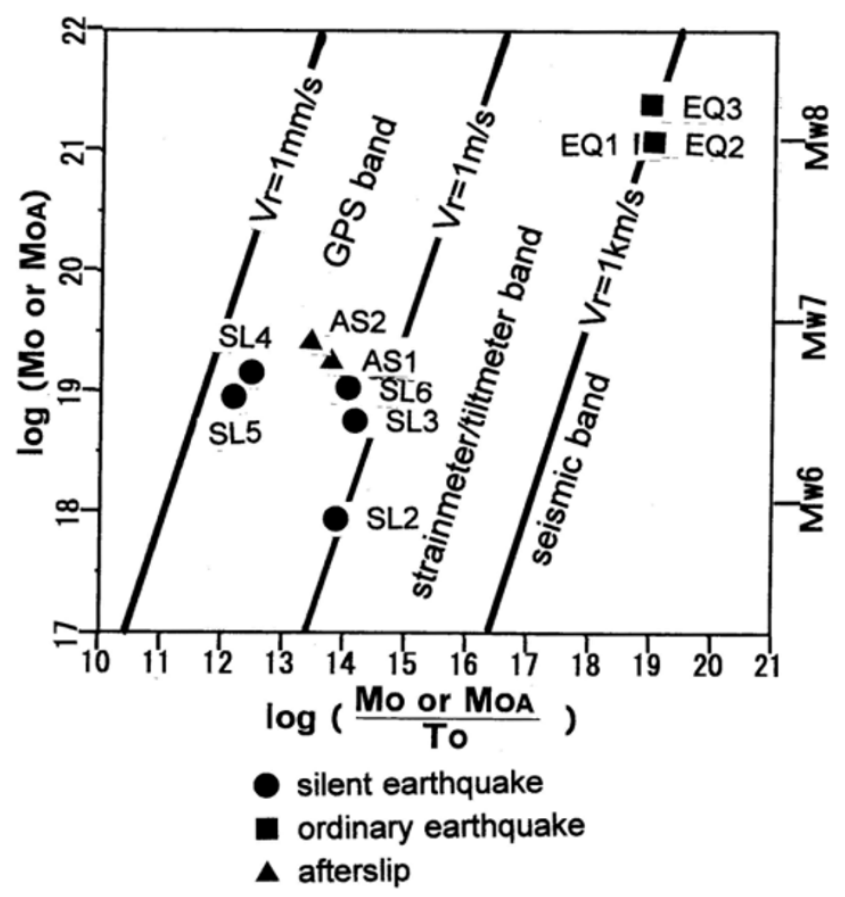

Fig. 3. Moment and moment-rate diagram. Vertical axis is static moment Mo or Moa $(\mathrm{Nm})$. Horizontal axis is moment rate $(\mathrm{Nm} / \mathrm{s})$, defined as Mo/To or Moa/To, where To is overall source duration time. Diagonal lines are iso- $V r$ lines, where $V r$ is a characteristic rupture velocity. Circles denote silent earthquakes, triangles afterslips, and squares ordinary $M w 8$ class earthquakes. See text for more details.

Studies of earthquake nucleation phase have been developed from laboratory experiments and numerical simulations based on constitutive laws of friction: e.g., Das and Scholz (1981), Dieterich (1979, 1986, 1994), Shibazaki and Matsu'ura (1998), Ohnaka and Shen (1999), and Kato and Hirasawa (1999). The rate- and state-dependent friction law is now widely accepted. Although several variations of the friction law were proposed, the friction parameter, $a-b$, in the so-called Dieterich-Ruina law is commonly used to describe quasi-static nucleation processes.

Yoshida and Kato (2003) and Kato (2003) performed numerical simulations of two block models having different friction. Following their results, we could regard silent earthquakes as one of the episodic phases in the stable-unstable transition zone in the later stage of the seismic cycle.

Thus, the following issues are raised which are associated with earthquake prediction.

(Issue-1) Do slow earthquakes occur with $M w a 7$ or greater and shorter source duration time of hours, filling the gap in (S7)? In other words, what is the link between the silent earthquakes in the stable-unstable transition zone and ordinary earthquakes in the seismogenic zone?

(Issue-2) Could we anticipate how silent earthquakes will grow?

\section{Empirical Source Time Function based on Lab- oratory Experiments}

Ohnaka and Shen (1999) carried out laboratory experiments on fault failure under compression on preexisting faults having different roughness. The earthquake nucleation phase consisted of three subphases, a quasi-static phase, an accelerating phase and a fast-speed dynamic rupture. The stage between the accelerating phase and the fast-speed dynamic rupture is called the critical stage.

Depending on the roughness of the fault surfaces, nucleation processes were quite different. In the case of a rough fault, growth rate was small and it took a long time to reach dynamic rupture, while growth rate was large for a smooth fault. However, they showed that, normalizing $\operatorname{Ln}(t)$ (size of nucleation zone) to $\lambda c$ (the roughness of fault surface, see Ohnaka and Shen, 1999), growth rate $V n(t)$ during the accelerating phase obeys a single comprehensive power low as

$$
\frac{V n(t)}{V s}=8.87 \times 10^{-29} \times\left(\frac{\operatorname{Ln}(t)}{2 \lambda c}\right)^{N K}
$$

where $N K=7.31$ and $V s$ is the S-wave velocity. The subscript $n$ denotes a quantity during the accelerating phase. It should be noted that the exponent $N K$ and the proportionality constant $8.87 \times 10^{-29}$ varies with stiffness, normal stress and stress rate and thus discussions below should be regarded as a zero-order approximation.

A fault parameter linearly related to geodetic observations is the moment, Mon $(t)(\mathrm{Nm})$, of the nucleation zone. We would like to transform Eq. (1) to a differential equation for $\operatorname{Mon}(t)$. For this purpose, we begin by deriving another power law which relates $\operatorname{Ln}(t)$ to Mon $(t)$ as below.

Ohnaka (2000) suggested relationships between seismic moment $M o$, critical distance $D c$ and critical length $L c$ as

$$
M o=10^{19} \times D c^{3}
$$



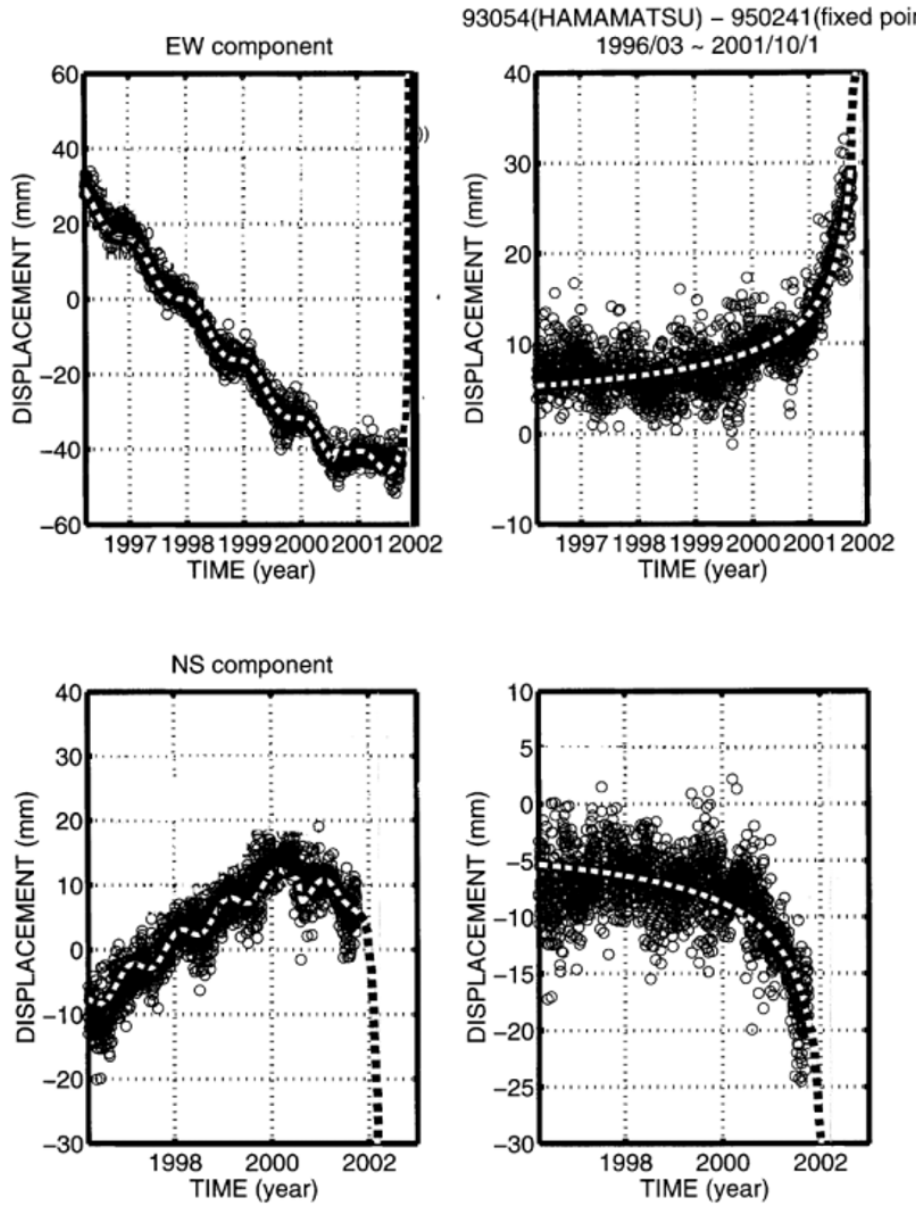

Fig. 4. EW (upper figure) and NS (lower) components of GPS horizontal displacements at Hamamatsu due to the Tokai silent earthquake (SL7 in Table 1). Vertical axis is the GPS displacement. Horizontal axis is time in years. Dots are daily values. Graphs on the left are original data. Graphs on the right show data with linear trends and annual variations removed. Broken lines are fitted curves for the period of 1996-2001 based on the time-to-failure analysis of Kawamura et al. (2002).

$$
M o=10^{9} \times L c^{3}
$$

where the units of proportionality coefficients are $\mathrm{N} / \mathrm{m}^{2}$. Note that $L c$ is the size of the nucleation zone at the critical stage in this paper but was its half length in Ohnaka and Shen (1999). The subscript $c$ denotes a quantity at the critical stage. Squaring both sides of (3), multiplying by (2) and taking the cube root, we have $M o=10^{1 / 3} \times 10^{12} \times$ $D c \times L c^{2}$. Assuming $W c$ (width of nucleation zone) $=$ $L c$ and $\mu$ (rigidity) $=4 \times 10^{10} \mathrm{~N} / \mathrm{m}^{2}$, we have the moment at the critical stage as $M o c=\mu \times L c \times W c \times D c=$ $4 \times 10^{10} \times L c^{2} \times D c$. Then, we have

$$
M o c=2 \times 10^{7} \times L c^{3} .
$$

Assuming the same relationship as Eq. (4) for the accelerating phase to replace $M o c$ and $L c$ with Mon $(t)$ and $L n(t)$, we have the second power law as

$$
\operatorname{Mon}(t)=2 \times 10^{7} \times \operatorname{Ln}(t)^{3} .
$$

The proportionality coefficient of $2 \times 10^{7}\left(\mathrm{~N} / \mathrm{m}^{2}\right)$ is one-order larger than that for ordinary earthquakes (e.g., Sato, 1979). Equation (5) is rewritten as

$$
\operatorname{Ln}(t)=g \times \operatorname{Mon}(t)^{1 / 3}
$$

where $g=\left(2 \times 10^{7}\right)^{-1 / 3}$. Substituting $\operatorname{Ln}(t)$ in Eq. (6) into Eq. (1), we have

$$
V n(t)=h \times \operatorname{Mon}(t)^{N K / 3}
$$

where $h=8.87 \times 10^{-29} \times V s \times[g /(2 \lambda c)]^{N K}$.

The nucleation zone expands by $d L n(t)=V n(t) d t$ during a time increment $d t$. Substituting (6) and (7) into $d \operatorname{Ln}(t)=V n(t) d t$, we have

$$
d t=\frac{d \operatorname{Ln}(t)}{V n(t)}=\frac{d \operatorname{Mon}(t)}{q \times \operatorname{Mon}(t)^{(N K+2) / 3}}
$$

where $q=(3 h / g)=3 \times 8.87 \times 10^{-29} \times V s \times$ $g^{N K-1} /(2 \lambda c)^{N K}$. From (8), we have the following ordinary differential equation as

$$
\frac{d M o n(t)}{d t}=q \times \operatorname{Mon}(t)^{(N K+2) / 3}
$$

assuming that $(N K+2) / 3$ and $M o n(t)$ are larger than 0 . Equation (9) describes growth during the accelerating phase. Integrating (8) from $t$ to $t_{d}$, we have

$$
t=t_{d}-T_{E}(t)
$$

where $t d$ is the time when $\operatorname{Mon}\left(t_{d}\right)$ is infinite and

$$
T_{E}(t)=\frac{3}{q \times(N K-1) \times \operatorname{Mon}(t)^{(N K-1) / 3}} .
$$




\section{Moment as a function of time}

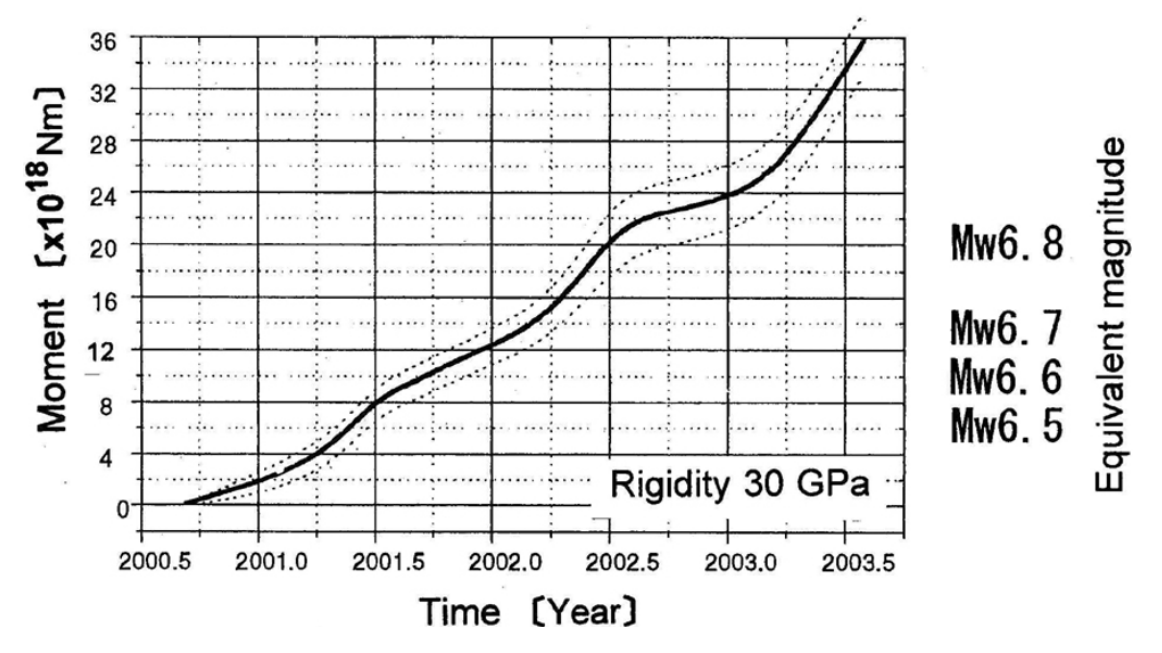

Fig. 5. Solid line is the moment of the Tokai silent earthquake as a function of time for the period from 2000 to 2003 , modified from GSI (2003b). Broken lines show a width of one standard deviation. Horizontal axis is years. Vertical axis is (left) static moment Moa and (right) its equivalent magnitude.

It should be noted that $q$ is inversely proportional to $\lambda c^{N K}$ and then $T_{E}(t)$ is proportional to $\lambda c^{N K}$.

Solving (10) and (11), we have

$$
\operatorname{Mon}(t)=\frac{\operatorname{Mon}\left(t_{0}\right)}{\left[1-\left(t-t_{0}\right) / T_{E}\left(t_{0}\right)\right]^{3 /(N K-1)}}
$$

where $t_{0}$ is a reference time and $t_{d}-t_{0}=T_{E}\left(t_{0}\right)$. The exponent of $3 /(N K-1)$ is around $1 / 2$ since $N K=7.31$ for the laboratory experiment of Ohnaka and Shen (1999). Equation (12) seems to be consistent with overall waveforms suggested by previous laboratory experiments and numerical simulations (e.g., figure 6 in Dieterich, 1986).

\section{Application of the Empirical Source Moment Function}

We try to fit synthetic waveforms using the source moment function of Eq. (12) to waveforms from silent earthquakes. This is quite similar to the time-to-failure analysis with an exponent of around -1 by Varnes (1989) and Main (1999) for predicting failure using seismicity prior to main shocks and volcanic eruptions.

The Tokai silent earthquake was first detected and observed to accelerate during the first half of 2001. Figure 4 shows the EW (upper figure) and the NS (lower) components of the GPS horizontal displacements at Hamamatsu. Broken lines are fitted curves for the period of 1996-2001 based on the time-to-failure analysis of Kawamura et al. (2002), suggesting a failure at the end of 2001 or beginning of 2002 . However, the event decelerated in the last half of 2001 and again accelerated in the first half of 2002, and now the $M w a$ of the event has grown larger than $M w a 7.0$, as illustrated in Fig. 5, which shows the moment of the Tokai silent earthquake as a function of time for the period from 2000 to 2003 (GSI, 2003b).

This analysis tells us that a single cycle of rupture growth process can be modeled with the source moment function (Eq. (12)) but the whole process including accelerations and deceleration can not be adequately modeled. This implies that the whole process is dependent on the heterogeneous distribution of the frictional properties and a quantitative prediction based on a fault constitutive relations requires proper numerical mapping of the frictional properties.

\section{Estimate of Roughness of the Subduction Inter- face}

We try to give order of magnitude estimates of the fault roughness by fitting synthetic displacements to observed waveforms of two recorded silent earthquakes.

Figure 6(A) shows GPS horizontal displacements due to the 1997 Bungo Channel silent earthquake (SL4). Vertical lines (E1)-(E5) indicate five earthquakes of $M w$ 5.8-6.7 which occurred in 1997 and 1998 in and around Kyushu Island. The silent earthquake was separated in space and time from these earthquakes (Hirose et al., 1999; Ozawa et al., 2001). Comparing the synthetic displacements in Fig. 6(B) with observed data at Saiki and Misho in (A), it can be concluded that there is a fair agreement for $\lambda c$ from $5 \mathrm{~m}$ to $8 \mathrm{~m}$ and a satisfactory fit for $\lambda c=6.5 \mathrm{~m}$ in the time window from (b) to (c).

Comparing synthetic crustal tilts to the observed data at Aikawa (AKW, borehole depth $95 \mathrm{~m})$, Fuchu (FCH, 2750 $\mathrm{m}$ ) and Iwatsuki (IWT, $3510 \mathrm{~m}$ ), we can obtain an order of magnitude estimate of $\lambda c=2 \pm 0.5 \mathrm{~m}$ for the source area of the 1989 Tokyo Bay silent earthquake (SL2).

We would like to emphasize that this is a unique way to estimate the roughness of subduction interface.

The stable-unstable transition zone corresponds to a boundary zone where $|a-b|$ is small between the seismogenic zone where velocity weakening $(a-b<0)$ dominates and the stable sliding zone where velocity hardening $(a-b>0)$ dominates. Based on numerical simulations of a two-degree-of-freedom block-spring model, Yoshida and Kato (2003) showed that slow-slip-events could occur where $|a-b|$ is small. Thus, the long source duration times of the silent earthquakes could be due to the small $|a-b|$ of the stable-unstable transition zone. 


\section{Bungo Channel Silent Earthquake}
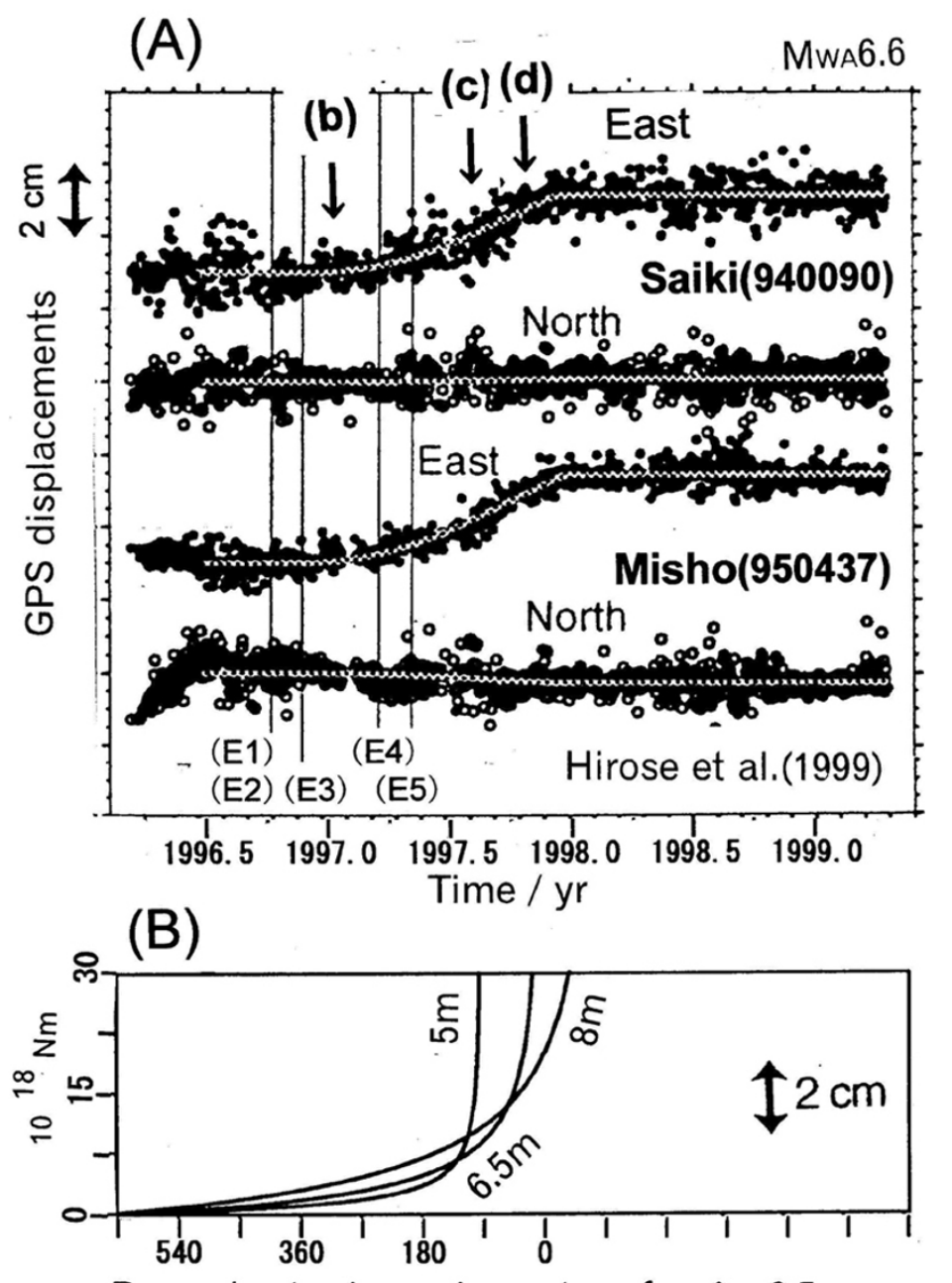

Day prior to dynamic rupture for $\lambda \mathrm{c} 6.5 \mathrm{~m}$

Fig. 6. (A) GPS horizontal displacements at Saiki (32.92N, 131.88E) on Kyushu Island and Misho (32.96N, 132.56E) on Shikoku Island in southwest Japan. Horizontal axis is time in years. Vertical axis is displacement in cm. Vertical lines indicate earthquakes on (E1) Oct. 18, 1996 (Mw 6.6, 30.47N, 131.29E, Depth $22 \mathrm{~km}$ ), (E2) Oct. 19, 1996 (Mw 6.7, 31.78N, 131.78E, Depth $22 \mathrm{~km})$, (E3) Dec. 02, 1996 (Mw 6.7, 31.76N, 131.72E, Depth 33 km), (E4) May 13, 1997 (Mw 6.0, 32.00N, 130.26W, Depth $16 \mathrm{~km}$ ) and (E5) June 25, 1998 (Mw 5.8, 34.43N, 131.35E, Depth 15 km). (b), (c) and (d) denote times when the nucleation phase was suggested to be initiated, decelerated and arrested, respectively. Modified from Hirose et al. (1999). (B) shows synthetic source moment $\operatorname{Mon}(t)$ at Misho for $\lambda_{c}$ of $5 \mathrm{~m}, 6.5 \mathrm{~m}$ and $8 \mathrm{~m}$. Vertical axis is moment in Nm, which is scaled to surface displacement at Misho.

\section{Estimate of the Magnitude of $a-b$}

We attempt another way to give a numerical estimate of the friction. Dieterich (1992) and Kato (2003) derived relationships between the size of a silent earthquake and the friction parameter $a-b$ from the Dieterich-Ruina law as

$$
a-b=-c \mu L s /(r c \times \sigma n)
$$

where $r c$ is the radius of a circular area of a silent earthquake, $\mu$ is rigidity, $L s$ is a characteristic slip, $\sigma n$ is normal stress, and $c=7 \pi / 24$. A major difficulty is that the values of $\sigma n$ and $L s$ are unknown. Here, we tentatively assume that $\sigma n$ is equal to the lithostatic stress. If the slip of a silent earthquake becomes larger than $D c$, it becomes a dynamic rupture. Thus, the slip of a silent earthquake should be less than $D c$, which gives a lower bound of $D c$. Here the slip of a silent earthquake is tentatively assumed to be equal to the characteristic slip $D c$. If we assume $D c / L s=10$ following Kuwahara et al. (1987), Ls can be assumed to be one-tenth
Table 3. Numerical estimate of friction parameter $a-b . r c$ is a radius of a circular area of a silent earthquake, which is assumed here to be a squared root of a faulting area over $\pi$. $\mu$ is rigidity, $L s$ characteristic slip, $\sigma n$ normal stress, and $c=7 p / 24$.

\begin{tabular}{cccccc}
\hline & $r c$ & $\begin{array}{c}\mu s \\
10^{10} \mathrm{Nm}\end{array}$ & $\begin{array}{c}\sigma n \\
\mathrm{~cm}\end{array}$ & $\begin{array}{c}a-b \\
\mathrm{MPa}\end{array}$ & $10^{-5}$ \\
\hline SL2 & 9.1 & 4 & 0.24 & 900 & -10 \\
SL4 & 33.9 & 4 & 1.8 & 600 & -3 \\
SL7 & 25.9 & 3 & 2.0 & 600 & -3 \\
\hline
\end{tabular}

of the slip of a silent earthquake. With Eq. (13) and these assumptions, we can obtain an order of magnitude estimates of $a-b$ as in Table 3. Considering the assumptions above, the numerical estimates should be regarded as lower limits of $|a-b|$.

The values are two-orders smaller than those determined 
from laboratory slip experiments (e.g., Kato and Hirasawa, 1999), which is consistent with the conclusion by numerical simulation of Yoshida and Kato (2003) suggesting that slowslip-events are liable to occur where $|a-b|$ is small.

\section{Concluding Remarks}

Major features of the slow-slip-events along the Nankai and the Sagami Troughs can be summarized as follows: There was a segregation between major asperities of $M w$ 8 class earthquakes and source areas of the slow-slip-events. Silent earthquakes occurred in the stable-unstable transition zone at depths of around $30 \mathrm{~km}$. Overall slips were less than $0.2 \mathrm{~m}$, one-order smaller than major asperities. There was a gap of 5-orders in the moment rates between the silent earthquakes and the $M w 8$ class ordinary earthquakes.

One problem in using these ideas for the prediction of great subduction zone earthquakes using numerical simulations based on constitutive laws of friction with distribution of the interplate friction is that there is not sufficient information to numerically map the heterogeneous distribution of friction. Two methodologies are attempted to obtain order of magnitude estimates of the roughness and the friction parameter in the source areas of the silent earthquakes. One method compares observed data to synthetic waveforms with a source time function described by Eq. (12). The other relates sizes of silent earthquakes to $a-b$, based on Eq. (13). However, the numerical estimations do not include sufficient information on the level of friction. These estimates should be regarded as a starting point toward future development of numerical mapping of the interplate friction.

Acknowledgments. The author would like to express his sincere thanks to Prof. T. Matsuzawa of Tohoku University, another anonymous referee and Prof. J. Mori of Kyoto University for helpful comments. The author would like to thank Profs. M. Ohnaka, N. Kato of the University of Tokyo, Prof. Kimata of Nagoya University, Dr. Y. Okada of the National Research Institute of Earth Sciences and Disaster Prevention and Dr. B. Shibazaki of the Building Construction Institute for discussions and suggestions during the course of this study, and Mr. Kawamura of Nagoya University for computing Fig. 4.

\section{References}

Beroza, G. C. and T. H. Jordan, Searching for slow and silent earthquakes using free oscillations, J. Geophys. Res., 95, 2485-2510, 1990.

Das, S. and C. Sholz, Theory of time-dependent rupture of the Earth, $J$. Geophys. Res., 86, 6039-6051, 1981.

Dieterich, J. H., Modelling of rock friction: 1. Experimental result and constitutive equations, J. Geophys. Res., 84, 2161-2168, 1979.

Dieterich, J. H., A model for the nucleation of earthquake slip, in Earthquake source mechanisms, M. EWING Ser. 6, edited by S. Das, J. Boatright, and C. H. Scholz, pp. 579-592, AGU, Washington, D.C., 1986.

Dieterich, J. H., Earthquake nucleation on faults with rate-dependent and state-dependent strength, Tectonophysics, 211, 115-134, 1992.

Dieterich, J. H., A constitutive law for rate of earthquake production and its application to earthquake clustering, J. Geophys. Res., 99, 2601-2618, 1994.

Dragert, H., K. Wang, and T. S. James, A silent slip event on the deeper Cascadia subduction interface, Science, 292, 1525-1528, 2001.

Ellsworth, W. L. and G. C. Beroza, Observation of the seismic nucleation phase in the 1995 Ridgecrest, California sequence, Geophys. Res. Inst., 25, 401-404, 1998.

Freymueller, J. T., S. Hreinsdottir, C. Zweck, and P. J. Haeussler, The 1998-2002 deep megathrust slip event, Alaska, AGU 2002 Fall Meeting, G61A-0972, 2002.

Fujii, Y., Vertical crustal movement in the Boso peninsula, South Kanto,
Japan, as deduced from the adjustment of a geodetic network with signals, Tectonophysics, 218, 309-322, 1993.

GSI, Crustal movements in the Kanto district, Report of the Coordinating Committee for Earthquake Prediction, 69, 138-175, 2003a (in Japanese).

GSI, Crustal movements in the Tokai district, Report of the Coordinating Committee for Earthquake Prediction, 70, 204-299, 2003b (in Japanese).

GSI, Crustal movements in the Chugoku, Shikoku and Kyushu districts, Report of the Coordinating Committee for Earthquake Prediction, 71, 680-694, 2004 (in Japanese).

Harada, S., Y. Nakagawa, I. Kawasaki, and T. Sagiya, A preliminary report on February, 1999, silent earthquake off Boso peninsula, central Japan, as revealed by GEONET, Abstracts 2000 Japan Earth and Planetary Science Joint Meeting, Da009, 2000 (in Japanese).

Hatanaka, Y., T. IIzuka, M. Sawada, A. Yamagiwa, Y. Kikuta, J. M. Johnson, and C. Roken, Improvement of the analysis strategy of GEONET, Bulletin of Geographical Survey Institute, 49, 11-37, 2003.

Hirose, H., K. Hirahara, F. Kimata, N. Fujii, and S. Miyazaki, A slow thrust slip event following the two 1996 Hyuganada earthquakes beneath the Bungo Channel, southwest Japan, Geophys. Res. Lett., 26, 3237-3240, 1999.

Hirose, H., K. Hirahara, and N. Fujii, Possible slow slip recurrence off Boso peninsula, Programme and Abstracts The seismological society of Japan 2001 Fall meeting, P140, 2001 (in Japanese).

Hirose, I., I. Kawasaki, Y. Okada, T. Sagiya, and Y. Tamura, A silent earthquake of December 9, 1989, in the Tokyo bay, as revealed by the continuous observation of crustal movements in the southern Kanto district, central Japan, Zisin, 53, 11-23, 2000 (in Japanese).

Hyndman, R. D. and K. Wang, Thermal constraints on the zone of major thrust earthquake failure: The Cascade subduction zone, J. Geophys. Res., 98, 2039-2060, 1993.

Ishida, M., Geometry and relative motion of the Philippine Sea plate and Pacific plate beneath the Kanto-Tokai district, Japan, J. Geophys. Res., 97, 489-515, 1992.

Ito, T., Y. Yoshioka, and S. Miyazaki, Interplate coupling in southwest Japan deduced from inversion analysis of GPS data, Phys. Earth Planet. Interiors, 115, 17-34, 1999.

Kanamori, H., Tectonic implication of the 1944 Tonankai and the 1946 Nankaido earthquakes, Phys. Earth Planet. Interiors, 5, 129-139, 1972.

Kanamori, H. and M. Kikuchi, The 1992 Nicaragua earthquake: A slow tsunami earthquake associated with subducted sediments, Nature, 361, 714-716, 1993.

Kanda, K., M. Takemura, and T. Usami, Inversion analysis of distribution of energy radiated from an earthquake fault based on the seismic intensity data, Zisin, 56, 39-58, 2003 (in Japanese).

Kato, N. and T. Hirasawa, Nonuniform and unsteady sliding of a plate boundary in a great earthquake cycle: A numerical simulation using a laboratory-derived friction law, Pure Appl. Geophys., 155, 93-118, 1999.

Kato, N., Repeating slip events at s circular asperity: Numerical simulation with a rate- and state-dependent friction law, Bull. Earthq. Res. Inst., 78, 151-166, 2003.

Kawamura, M., K. Yamaoka, H. Hirose, and K. Hirahara, Time-to-failure analysis for the anomaly of the crustal movement in the Tokai region, Abstracts 2000 Japan Earth and Planetary Science Joint Meeting, S046P003, 2002 (in Japanese).

Kawasaki, I., Y. Asai, Y. Tamura, T. Sagiya, N. Mikami, Y. Okada, M. Sakata, and M. Kasahara, The 1992 Sanriku-Oki, Japan, ultra-slow earthquake, J. Phys. Earth, 43, 105-116, 1995.

Kawasaki, I., Y. Asai, and Y. Tamura, Space-time distribution of interplate moment release including slow earthquakes and the seismo-geodetic coupling in the Sanriku-oki region along the Japan trench, Tectonophysics, 300, 267-283, 2001.

Kikuchi, M., M. Nakamura, and K. Yoshikawa, Source rupture process of the 1944 Tonankai earthquake and the 1945 Mikawa earthquake derived from low-gain seismograms, Earth Planets Space, 55, 159-172, 2003.

Kimata, F., K Hirahara, and N. Fujii, Interplate coupling changes in the Tokai region, Japan, estimated from the vertical movements by leveling and tide gauge during 1960-2002, AGU 2002 Fall Meeting, G61A-0978, 2002.

Kuwahara, Y., M. Ohnaka, K. Yamamoto, and T. Hirasawa, Earthquake faulting and fault surface topography, Report of collaborative research project on Fractal and Fracture phenomena, Mathematical seismology II, The Institute of Statistical Mathematics, 36-48, 1987 (in Japanese).

Lowry, A. R., K. M. Larson, V. Kostoglodov, and R Bilham, Transient fault slip in Guerrero, southern Mexico, Geophys. Res. Lett., 28, 3753-3756, 2001.

Linde, A. T., K. Suyehiro, S. Miura, I. S. Sacks, and A. Takagi, Episodic 
aseismic slip, stress distribution and seismicity, Nature, 334, 513-515, 1988.

Main, I. G., Applicability of time-to-failure analysis to accelerated strain before earthquakes and volcanic eruptions, Geophys. J. Int., 139, F1-F6, 1999.

Miyoshi, T. and K. Ishibashi, Geometry of the upper surface of the Philippine sea slab, in Proc. of Physics of arc and back arc associated with the subduction of the Philippine sea plate, edited by I. Nakanishi, Disaster Prevention Institute, Kyoto University, pp. 127-137, 2002 (in Japanese).

Nakamura, M., H. Watanabe, T. Konomi, S. Kimura, and M. Miura, Characteristic activities of subcrustal earthquakes along the outer zone of southwest Japan, Annuals of the Disaster Prevention Research Institute, 40, B, 1-20, 1997 (in Japanese).

Obara, K., Nonvolcanic deep tremor associated with subduction in southwest Japan, Science, 296, 1679-1681, 2002.

Ohnaka, M. and L.-F. Shen, Scaling of the rupture process from nucleation to dynamic propagation: Implications of geometric irregularity of the rupturing surfaces, J. Geophys. Res., 104(B1), 817-844, 1999.

Ohnaka, M., A physical scaling relation between the size of an earthquake and its nucleation zone size, Pure and Applied Geophysics, 157, 22592282, 2000.

Ozawa, S., M. Murakami, and T. Tada, Time-dependent inversion study of the slow thrust event in the Nankai trough subduction zone, southwest Japan, J. Geophys. Res., 787-802, 2001.

Pelayo, A. M. and D. W. Wiens, Tsunami earthquake: Slow thrust-faulting events in the accretionary wedge, J. Geophys. Res., 97(B11), 1532115337, 1992.

Sagiya, T. and W. Thatcher, Coseismic slip resolution along a plate boundary megathrust: The Nankai Trough, southwest Japan, J. Geophys. Res.,
104, 1111-1129, 1999.

Sagiya, T., Interplate coupling in the Tokai district, central Japan, deduced from continuous GPS data, Geophys. Res. Lett., 26, 2315-2318, 1999.

Sagiya, T., Interplate coupling in the Kanto District, central Japan, and the Boso Silent earthquake in May 1996, PAGEOPH, 2004 (in press).

Sato, R., Theoretical basis on relationships between focal parameters and earthquake magnitude, J. Phys. Earth, 27, 353-372, 1979.

Seno, T., S. Stein, and A. Gripp, A model for the motion of the Philippine Sea plate consistent with NUVEL-1 and geological data, J. Geophys. Res., 98, 17941-17948, 1993.

Shibazaki, B. and M. Matsu'ura, Transition process from nucleation to high speed rupture propagation: Scaling from stick-slip experiments to natural earthquakes, Geophys. J. Int., 132, 14-30, 1998.

Tanioka, Y. and K. Satake, Coseismic slip distribution of the 1946 Nankai earthquake and aseismic slips caused by the earthquake, Earth Planets Space, 53, 4, 235-241, 2001.

Varnes, D. J., Predicting earthquakes by analyzing accelerating precursory seismic activity, Pure Appl. Geophys., 130, 661-686, 1989.

Wald, D. J. and P. G. Somerville, Variable-slip rupture model of the great 1923 Kanto, Japan, Earthquake: Geodetic and body-waveform analysis, Bull. Seism. Soc. Am., 85, 159-177, 1995.

Yagi, Y., M. Kikuchi, and T. Sagiya, Co-seismic slip, post-seismic slip, and aftershocks associated with two large earthquakes in 1996 in Hyuganada, Japan, Earth Planets Space, 53, 793-803, 2001.

Yoshida, S. and N. Kato, Episodic aseismic slip in a two-degree-of-freedom block-spring model, Geophys. Res. Lett., 30, 13, 1681-1684, 2003.

I. Kawasaki (e-mail: kawasaki@rcep.dpri.kyoto-u.ac.jp) 